\title{
Eine Welsche in Muttenz
}

\section{Julia Rippstein}

Online- und Print-Redaktorin

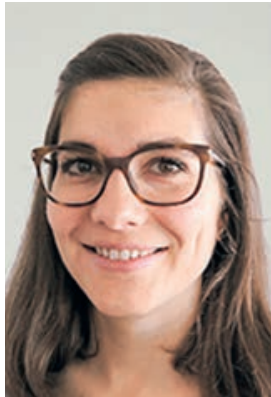

Brückenbauerin - ein grosses Wort! Ich erkenne mich jedoch ziemlich gut in dem, was es bedeutet, wieder. Aufgewachsen in der Romandie, sprach ich trotz Deutschschweizer Vater zu Hause immer Französisch. Die deutschsprachige Kultur war immer ziemlich nah. Aber ich identifizierte mich nicht mit ihr. Wie vielen Westschweizern erschien mir das Land jenseits des Röstigrabens beinahe wie ... jenseits des Atlantiks. Vom Dialekt ganz zu schweigen! Mit den Jahren kam es zu einer Annäherung an diese geheimnisvolle Region, wo vier aufeinanderfolgende Konsonanten wie ein gutturales Räuspern ausgesprochen werden (was mir heute leichtfällt!). Der «Wendepunkt» kam, als ich ein Studienjahr in Zürich absolvierte. Eine unvorhergesehene Begegnung mit Amors Pfeil und das «Unglück» - wie einige meiner (Westschweizer) Freunde lachend sagen - war geschehen. Liebe kümmert sich nicht um den Röstigraben, dafür bin ich der beste Beweis. Nach einigen Lehr- und Wanderjahren durch die gesamte Schweiz fasste ich den Entschluss, mich 250 Kilometer von jenem Ort niederzulassen, an dem ich aufgewachsen bin mein französisch gefärbtes «Schwiizerdütsch» im Gepäck.

Vor meinem «Sprung» über die Saane vor jetzt bald vier Jahren sah ich mich durch einige Erlebnisse gezwungen, ein paar «kulturelle Anpassungen» vorzunehmen. Ein kräftiger Händedruck anstelle von Begrüssungsküsschen. Die unsinnig scheinende Höflichkeitsfrage "Isch do no frei?» im Zug, wenn das ganze Abteil leer ist, Abendessen um Punkt 18 Uhr, die obligatorische Platzreservierung im Kino oder die unumgängliche Fasnacht ... Einen Reisenden im Zug zu fragen, ob einer der drei leeren Sitze neben ihm noch frei sei, ist kein Akt von Übereifer oder Blödheit, sondern vielmehr ein Zeichen von Rücksichtnahme und Zuvorkommenheit der Deutschschweizer den anderen gegenüber. Ihr Gemeinschaftssinn ist deutlich entwickelter als bei den eher individualistisch veranlagten Westschweizern. Ja, das habe ich wirklich zu schätzen gelernt. Inzwischen frage ich auch nach, ob der Platz neben jemandem noch frei ist.

Ich würde lügen, wenn ich sagte, dass ich nichts aus der Romandie vermisse. Eine gewisse unbekümmerte Leichtigkeit, die wortlos geduldete Viertelstunde Verspätung, eine kleine Prise Ironie ... Seit ich in der
Deutschschweiz sesshaft bin, erkläre ich, wer die Welschen sind: Nein, wir sind keine Franzosen (was für eine Idee!), wir geniessen nicht jeden Abend einen Apéro und wir haben das Eidgenössische Schwingund Älplerfest 2019 kaum verfolgt (warum auch, ohne Westschweizer Kandidat!). Wir kennen weder die Lieblingskomiker (Giacobbo wer?!) noch die angesagten Sänger aus der Deutschschweiz. Wir kämen nicht mal auf die Idee, SRF einzuschalten (TV-mässig ziehen wir die Franzosen vor). Ab und zu ist es also angebracht, einiges wieder etwas "geradezurücken" und die Deutschschweizer daran zu erinnern, dass sie zwar die Mehrheit bilden (65\%), aber noch lange nicht allein sind in der kleinen Schweiz. Die Westschweizer fordern ihren Anteil am "Schweizer Kuchen». Sie essen ihn jedoch anders als ihre deutschsprachigen Landsleute.

Westschweizerin oder Deutschschweizerin? Eine Mischung aus beiden, wenngleich ich mich ganz als Westschweizerin fühle - und sei es nur, weil Franzö-

\section{Die Westschweizer fordern ihren Anteil am} "Schweizer Kuchen". Sie essen ihn jedoch anders als ihre deutschsprachigen Landsleute.

sisch meine Muttersprache ist. Aber ist das so wichtig? Mir ist es wichtig, die Werte der einen Region der anderen zu vermitteln und umgekehrt. Beide Sprachregionen kennen sich leider immer noch zu wenig, obwohl sie viel voneinander zu lernen hätten. Im Hinblick auf einen besseren nationalen Zusammenhalt leiste ich als neue französischsprachige Redaktorin der Schweizerischen Ärztezeitung (die erste, welche Ehre!) einen bescheidenen, wenngleich nicht zu unterschätzenden Beitrag. Von Anfang an fühlte ich eine gewisse Dankbarkeit seitens meiner Kollegen: Eine Westschweizerin unter uns - endlich! Wie ein Chamäleon, das sich beiden Seiten des Röstigrabens mühelos anpasst, habe ich nun die schöne und herausfordernde Aufgabe, den französischsprachigen Teil der Zeitschrift zu verstärken, die Westschweizer Leserschaft intensiver anzusprechen und den Deutschschweizern dabei gleichzeitig innovative, im «Welschland» geborene Gesundheitsprojekte näherzubringen. Anders gesagt, Brücken zu bauen zwischen beiden Sprachregionen. 